\title{
Forecasting and Management of Hop Downy Mildew
}

David H. Gent, U.S. Department of Agriculture-Agricultural Research Service, Forage Seed and Cereal Research Unit, and Department of Botany and Plant Pathology, Oregon State University, Corvallis 97331; Cynthia M. Ocamb, Department of Botany and Plant Pathology, Oregon State University, Corvallis 97331; and Joanna L. Farnsworth, Department of Crop and Soil Science, Oregon State University, Corvallis 97331

\begin{abstract}
Gent, D. H., Ocamb, C. M., and Farnsworth, J. L. 2010. Forecasting and management of hop downy mildew. Plant Dis. 94:425-431.

Downy mildew of hop (Humulus lupulus), caused by Pseudoperonospora humuli, is managed in the Pacific Northwestern United States by regular application of fungicides. A degree-day model that forecasts the first emergence of shoots systemically infected with $P$. humuli (termed basal spikes) and a risk index for secondary spread of the disease were evaluated over four seasons in western Oregon. In surveys conducted in 34 hop yards, the predicted first spike emergence occurred on average 11.6 days (median 12 days) after spike emergence using a simple average degree-day model (base temperature $6.5^{\circ} \mathrm{C}$ ) developed for Washington State. Predictions based on a single sine model (base temperature $6^{\circ} \mathrm{C}$ ) provided on average 4.9 days (median -0.5 days) of advanced warning before the first spike emerged. Downy mildew severity in a previous season was negatively correlated with the degree-day emergence date of spikes the following year $(r=$ -0.39 ). In experimental plots, disease severity was significantly greater where fungicide applications were timed using a risk index compared to routine fungicide applications in 2005 and 2007, but statistically similar between these treatments in 2006 and 2008. However, in 2006, 2007, and 2008, treatments initiated using a degree-day threshold resulted in an area under the disease progress curve similar to or smaller than in treatments with routine fungicide applications. Model-aided treatments required four fewer fungicide applications compared to routine fungicide applications. These studies indicate that downy mildew can be managed effectively with fewer fungicide applications than currently made by hop growers in this region if fungicide applications are timed to coincide with the predicted emergence of basal spikes and subsequent disease risk forecasts.
\end{abstract}

Downy mildew of hop (Humulus lupulus), caused by Pseudoperonospora humuli (Miy. et Tak.) Wils., is an important disease in most regions of hop production in the Northern Hemisphere $(20,28)$ and Argentina (23). The disease can cause direct losses in cone yield if the trained bines (shoots that climb by means of helical growth around a support) and cone-bearing lateral branches become infected, which arrests development of these shoots and prevents cone formation. Infections of inflorescences and developing cones reduce crop quality and marketability due to discoloration of the cones and diminished levels of bittering acids (28). In susceptible

Corresponding author: David H. Gent E-mail: gentd@onid.orst.edu

Mention of a trademark, proprietary product, or vendor does not constitute a guarantee or warranty of the product by the USDA and does not imply its approval to the exclusion of the products or vendors that may also be suitable.

Accepted for publication 9 December 2009.

doi:10.1094/PDIS-94-4-0425

This article is in the public domain and not copyrightable. It may be freely reprinted with customary crediting of the source. The American Phytopathological Society, 2010. cultivars, the disease also may cause a crown rot that can lead to weak growth during ensuing seasons $(1,2)$ and plant death $(30,31)$.

Management of downy mildew is dependent on regular application of fungicides $(1,7,16)$ supplemented by sanitation practices such as spring crown pruning $(24,28,31)$. Disease outbreaks are favored by wetness on foliage, high humidity, and temperatures ranging from 8 to $23^{\circ} \mathrm{C}$ $(11,12,25)$. During such conditions, the pathogen may infect leaves and shoots, leading to systemic infection that may extend into the hop crown and root system $(1,30)$. Various disease forecasting systems have been developed to aid in timing fungicide applications for downy mildew in Washington State and Europe $(8,9,11,12$, 14,22,26). Royle $(25,26)$ developed a downy mildew risk index in England that estimates disease risk based on a 2-day moving average regression equation of relative humidity, rain, and temperature during periods of rain. The model was implemented operationally in the United Kingdom with an empirical management action threshold (26), and a version of the model is commercially available (Adcon Telemetry, Klosterneuburg, Austria). This model has not been evaluated rigorously in the United States, and it is unclear when fungicide applications should begin during the season with this model in U.S. regions of hop production.

$P$. humuli perennates as mycelia in systemically infected crowns, from which the pathogen invades developing shoot buds and emerges the following season in systemically infected shoots $(1,2,30)$. The systemically infected basal shoots that emerge in the spring are termed "basal spikes" due to their stunted, spike-like appearance. Johnson (8) developed two growing degree-day models (based upon air and soil temperature) that predict the first emergence of basal spikes in the semiarid hop production regions in Washington. These models predict that the first basal spike will appear after 111.3 (airtemperature) or 88.7 (soil temperature) degree-days (base $6.5^{\circ} \mathrm{C}$ ) accumulate starting 1 February (the "biofix" date) or after the last 5-day cold period from 1 February, known as the "cold period rule" (8), for highly susceptible cultivars (i.e., Cluster types). Since downy mildew epidemics do not occur annually in Washington $(9,12)$, these models were promoted as tools to enhance scouting efforts. In hop production regions where epidemics of downy mildew occur annually, such as the cool, maritime climate of western Oregon, these models may successfully predict when fungicide applications should be initiated each spring to protect plants from earlyseason spread of inoculum produced on newly emerged basal spikes.

In this research, our objective was to validate forecasting systems for downy mildew in western Oregon. Experiments were conducted over four field seasons to validate an air temperature degree-day model (8) for predicting emergence of basal spikes and a risk index for secondary spread of the disease.

\section{MATERIALS AND METHODS}

Experimental plots. Experiments were conducted during 2005 to 2008 in small plots near Corvallis, OR. Plots were established in a hop yard planted in 1999 to the downy mildew-susceptible cultivar Nugget (5). Hills (groups of usually 4 to 6 propagative units planted together) were arranged on a 2.1-m grid (considered a narrow spacing for hop yards in the United States) under a 5-m-tall trellis. Each plot contained at least three hills, and plots were arranged in a randomized complete 
block design with three to four replications. Each plot was separated by one or two rows of plants treated with fungicides that are not effective on hop downy mildew.

Plants were maintained according to standard horticultural practices for hop production in the Pacific Northwestern United States (16). Early spring growth was removed by a single application of carfentrazone-ethyl (Aim EW, FMC Corp., Philadelphia, PA; $33.6 \mathrm{~g}$ a.i./ha) on 20 April, 11 April, 30 March, and 17 April in 2005, 2006, 2007, and 2008, respectively. Superfluous basal foliage was desiccated using carfentrazone-ethyl on 29 May, 22 June, and 23 May in 2006, 2007, and 2008, respectively. This practice reduces the severity of downy mildew by removing inoculum $(16,24)$ and is practiced routinely in hop production. An application of carfentrazone-ethyl was not made in 2005 because disease pressure was relatively low and removing basal foliage would have obfuscated treatment differences. Irrigation was supplied by sprinklers every 7 to 14 days as needed for crop development, ranging between 2.5 and $5 \mathrm{~cm}$ per irrigation.

Weather conditions near the hop yard were monitored and recorded every $15 \mathrm{~min}$ with a Campbell Scientific CR10X datalogger (Campbell Scientific, Inc., Logan, UT) located approximately $200 \mathrm{~m}$ from the field. Air temperature and relative humidity were measured $1.5 \mathrm{~m}$ aboveground with a model HMP45C temperature and relative humidity probe. Temperature and relative humidity for 15-min periods were obtained by averaging measurements taken at 5-min intervals. Rainfall was measured with a model TE525 tipping bucket rain gauge mounted $5 \mathrm{~m}$ aboveground at the top of the hop trellis.

Degree-day model validation. Plants in each plot and adjacent plants in buffer rows were examined two to five times per week beginning from shoot emergence until the first primary spike was observed. A total of 161 hills were inspected during each disease assessment. Additionally, five (2005) to 10 (2006 to 2008) commercial hop yards (34 yards in total) were surveyed one to three times each week to detect the appearance of the first primary basal spike. Yards included in the survey were planted to cultivars Nugget (17 yards), Willamette (15 yards), and Glacier (2 yards) and were all located in Marion County in western Oregon. Data are excluded for one yard planted to cultivar Willamette in which downy mildew was not detected for the entire season in 2007. Three yards surveyed in 2005 also were surveyed from 2006 to 2008. All yards surveyed in 2006 were included in surveys in 2007 and 2008. Spring pruning of crowns (3) was done mechanically in 18 yards and chemically in 16 yards.

Each yard was divided into strata by dividing the number of rows by 20 (rounded up to the nearest integer). One transect (row) was sampled arbitrarily from each of two strata per yard. Two hundred plants in each transect were inspected, unless the row contained fewer than 200 plants. Yards ranged in size from 3 to 20 ha. In a subset of 29 yards, after downy mildew was detected, disease assessments continued every 7 to 21 days throughout the season. For these disease assessments, the number of basal spikes was counted on at least 50 plants per transect unless the row contained fewer than 50 plants. At least five disease assessments were conducted each season to allow for calculation of the relative area under the disease progress curve (RAUDPC; 15) based on disease incidence (proportion of infected plants in a yard). Growers provided information on the cultivar, cultural practices, and pesticide applications for each yard.

Degree-days based on the air temperature model of Johnson (8) were calculated from weather data obtained from the nearest regional weather station to each yard available through the Oregon State University Integrated Plant Protection Center website. The distance to the nearest weather station varied from 6.1 to $24.5 \mathrm{~km}$. The "cold period" rule (8) was not implemented based on results of preliminary experiments. Degree-days were calculated by four methods and compared. These methods included calculating a simple averaging function as described by Johnson (8) and using a single sine function with a base temperature of $5,5.5$, or $6^{\circ} \mathrm{C}$ and starting (biofix) dates of 1 January or 1 February. Simple average degree-days were calculated by adding the maximum and minimum temperatures, dividing by two, and then subtracting the base temperature from the result. For calculating degree-days using a single sine function, the minimum and maximum temperatures for a day are used to produce a sine curve over a 24-h period. Degree-days for that day are then obtained by calculating the area above the threshold and below the curve. Predictive thresholds for the sine function models were derived from the median accumulated degree-days when the first sporulating basal spike was detected. Predicted and actual appearance dates of the first basal spike were compared and used to calculate measures of model performance such as the mean, median, and range of degree-days and calendar-days.

To further evaluate and compare model performance, an empirical cumulative density function was fit to data of the difference in observed degree-days versus predicted degree-days at spike emergence. Based on results of model performance (described below), the simple average degree-day model and single sine model with base temperature of $6^{\circ} \mathrm{C}$ were included in these analyses. Several distributions were fit to the data and evaluated before selecting a three-parameter log- normal model as a reasonable distribution for the cumulative density function. Analyses were conducted using Minitab version 14 (Minitab Inc., State College, PA).

Associations between downy mildew severity in the current and previous season and first emergence of spikes were compared by Pearson's correlation coefficient (Systat Software, Inc., San Jose, CA). The median degree-days at spike emergence was compared in yards where disease severity in the previous season, as measured by the RAUDPC, was above or below the median for all yards using Mood's median test (29) in Minitab version 14.

Disease risk index validation. The infection risk index developed by Royle $(25,26)$ was evaluated in the experimental plots described above. Treatments evaluated were fungicide applications made preventatively (standard), timed according to the disease risk index, timed according to the disease risk index coupled to a degree-day model to initiate applications (evaluated during 2006 to 2008), and a nontreated control. The risk index was implemented with a set of hierarchical rules:

(i) If no rain was recorded during a 48-h period, then the index $=0$, else;

(ii) If mean temperature was less than $8^{\circ} \mathrm{C}$ during a period of rain, then the index $=0$, else;

(iii) Index $=-63+(22 * \mathrm{RH})+$ (84*Rain), where "RH" is the number of hours of relative humidity $\geq 90 \%$ in the previous $48 \mathrm{~h}$, and "Rain" is millimeters of rain in the previous $48 \mathrm{~h}$. The model was calculated daily with weather data collected from 4 P.M. to 4 P.M. for a 48 -h period. An empirical threshold of 500 "risk units" was considered to be a severe infection event that warranted a fungicide application (26).

Each plot received a rotation of applications of fosetyl-Al $(5.6 \mathrm{~kg} / \mathrm{ha}$ Aliette WDG, Bayer CropScience, Research Triangle, NC), cymoxanil and copper hydroxide $(0.22 \mathrm{~kg} / \mathrm{ha}$ Curzate 60DF and 1.68 kg/ha Kocide 2000, E. I. du Pont de Nemours and Company, Wilmington, DE), and trifloxystrobin and copper hydroxide $(0.28 \mathrm{~kg} / \mathrm{ha}$ Flint, Bayer CropScience; and $1.68 \mathrm{~kg} / \mathrm{ha}$ Kocide 2000). It was assumed that fosetyl-Al provided 14 days of protection against downy mildew, whereas cymoxanil and copper hydroxide, and trifloxystrobin and copper hydroxide provided 7 days of protection based on the manufacturers' recommendations and use patterns in Oregon (D. H. Gent, unpublished data). All fungicides were applied at the highest rates allowed based on their respective registrations for use in hop. Although resistance to fosetyl-Al has been reported in $P$. humuli in western Oregon, management of downy mildew is still possible when the highest rate specified on the Aliette WDG label is used (18). Phenylamide fungicides were not included in the 
experiments due to widespread resistance to these compounds in $P$. humuli $(4,6,13)$. Applications were made with an Eagle BP40 backpack sprayer (Eagle-1 Manufacturing, Monroe, WA). Application volume increased with plant development each season, and ranged between 374 liters/ha in early to mid-spring to 1,515 liters/ha during and after burr development.

Fungicides used in plots receiving the grower standard treatment were applied every 7 to 14 days (depending on the fungicide in the rotation), beginning when shoots were approximately $15 \mathrm{~cm}$ tall, which occurred on 22 May, 28 April, 16 April, and 1 May in 2005 to 2008, respectively. Application ceased in mid-July, typical of commercial management practices for downy mildew. The grower standard treatment included six (2005) to 10 (2007) applications each year.

In the plots receiving the risk index treatment, fungicide applications began at the first predicted severe infection event (i.e., at least 500 risk units) after shoots were at least $15 \mathrm{~cm}$ tall. This corresponded to 22 May, 8 May, 16 April, and 24 May from 2005 to 2008, respectively. Subsequent applications were made when the risk index was at least 500 risk units and the previous fungicide application had occurred more than 7 to 14 days earlier in these plots, as described above. The total number of applications each year ranged from three (2005) to five (2007).

In the plots receiving the first fungicide application according to a degree-day model, two different fungicide programs were evaluated. In both programs, the first application was made after the accumulation of 111 degree-days (base $6^{\circ} \mathrm{C}$ ) using a single sine function beginning from a biofix date of 1 February. For "degree-day/ copper", the first fungicide applied was copper hydroxide, and for "degree-day/fosetylAl", the first fungicide applied was fosetylAl. Both treatments were included to evaluate the effect of fungicide mode of action of the first application on the efficacy of these treatments. Only the degree-day model based on a single sine function and base $6^{\circ} \mathrm{C}$ was evaluated in these experiments based on the greater mean forecast lead time (5.3 days) of this model compared to degree-day models with base temperatures of 5.5 or $5^{\circ} \mathrm{C}$ (described below).

The first application made to plots receiving these treatments occurred on 7 April, 17 March, and 12 April in 2006, 2007, and 2008, respectively. These treatments were not evaluated in 2005. In each year, these initial applications based on the degree-day model occurred before shoots were chemically desiccated with carfentrazone-ethyl as described above. Subsequent applications were made when the risk index was at least 500. However, in 2007, the second application made to plots receiving the degree-day/copper and degreeday/fosetyl-Al treatments occurred on 26
April (instead of 4 May as occurred with the risk index treatment) due to a miscalculation of the risk index on 26 April.

Disease severity was assessed by counting the number of primary and secondary basal spikes in each hill. Three disease assessments were conducted in 2005. During 2006 to 2008, disease assessments were conducted every 1 to 3 weeks, depending on field accessibility due to pesticide applications. After training, the density of systemically infected trained shoots and lateral branches (aerial spikes) was determined by counting these shoots on each hill. At harvest, 50 cones were collected from each hill and examined for signs of downy mildew. A cone was considered diseased if sporangia and sporangiophores of $P$. humuli were observed.

Disease severity data were summarized by calculating AUDPC for each plot. Calculations were conducted using a macro available in Sigma Plot version 11. AUDPC values were analyzed by a mixed effects model using the MIXED procedure in SAS version 9.2 (SAS Institute, Inc., Cary, NC). Experimental blocks were considered a random effect in the model. Disease incidence data from cones were logtransformed to normalize standard errors and variances before analysis.

\section{RESULTS}

Degree-day model validation. Downy mildew was detected in 34 of the 35 yards surveyed from 2005 to 2008. Spikes were detected beginning on 14 March, 24 March, 13 March, and 14 March, respectively. Within each year, spike emergence among yards occurred over a duration of 27 days in 2006 to 54 days in 2008. The RAUDPC varied from 0 to 0.93 among yards, with mean 0.15 (standard error 0.01 ) and median 0.06 .

Table 1. Characteristics of degree-day models for prediction of the first emergence of hop shoots systemically infected with Pseudoperonospora humuli in western Oregon

\begin{tabular}{|c|c|c|c|c|}
\hline & \multirow[b]{2}{*}{ Simple average $\mathrm{e}^{\mathrm{x}}$} & \multicolumn{3}{|c|}{ Sine function ${ }^{x}$} \\
\hline & & $6.0^{\circ} \mathrm{C}$ & $5.5^{\circ} \mathrm{C}$ & $5.0^{\circ} \mathrm{C}$ \\
\hline \multicolumn{5}{|l|}{ Degree-days } \\
\hline Mean & 90.7 & 142.2 & 157.9 & 179.6 \\
\hline Median & 75.8 & 115.7 & 130.7 & 150.2 \\
\hline Range & 165.9 & 199.5 & 214.3 & 233.6 \\
\hline Standard deviation & 49.4 & 60.7 & 65.4 & 71.1 \\
\hline Relative standard deviation $(\%)^{\mathrm{y}}$ & 0.55 & 0.43 & 0.41 & 0.40 \\
\hline \multicolumn{5}{|c|}{ Difference between predicted and observed emergence (days) ${ }^{\mathrm{z}}$} \\
\hline Mean & -11.6 & 5.3 & 5.0 & 4.9 \\
\hline Median & -12.0 & 0 & 0 & -0.5 \\
\hline Range & 80.0 & 60.0 & 60.0 & 57.0 \\
\hline Standard deviation & 20.9 & 16.7 & 16.6 & 16.3 \\
\hline Relative standard deviation (\%) & 1.80 & 3.2 & 3.3 & 3.3 \\
\hline
\end{tabular}

${ }^{x}$ Degree-days were calculated by adding the maximum and minimum temperatures for a day, dividing by two, and then subtracting the base temperature $\left(6.5^{\circ} \mathrm{C}\right)$ from the result starting from 1 February (8), or by use of a sine function with one of three base temperatures. Data are from a total of 34 hop yards surveyed in western Oregon from 2005 to 2008.

y Relative standard deviation is the absolute value of the standard deviation divided by the mean.

${ }^{\mathrm{z}}$ Median accumulated degree-days (Celsius) for emergence of diseased shoots was used as the threshold for evaluation of the mean, median, range, standard deviation, and relative standard deviation of sine function models. Negative numbers indicate that diseased shoots emerged before a degree-day
Averaged across all years, the first basal
spike was detected after the accumulation of a mean of 90.7 degree-days (median 75.8) based on the model developed for (Table 1). Mean degree-days temperatures of $5,5.5$, or $6^{\circ} \mathrm{C}$ ranged from 142.2 to 179.6 , with corresponding medians of 115.7 to 150.2 . The range and relaeviation of the models were with degree-days calculated using a sine function versus the simple average model.

e estimate the first emergence date of spikes and was compared to the Washington model ("simple average" Table 1), which thresholds, the Washington model for prespike emergence occurred on averemergence. Predictions were, on average, earlier using a sine function model, which
provided on average 4.9 to 5.3 days (median 0 to -0.5 days) of advanced warning the first spike emerged. Relative were larger for the sine function model than for the simple average model due to function model measured in calendar days sine function with a base of $6^{\circ} \mathrm{C}$ was sefor further analysis due to the greater ated with this model compared to degreeday models with bases of 5.5 or $5^{\circ} \mathrm{C}$.

Of the 34 yards with downy mildew, the irst spike emerged before the degree-day model and 15 yards using the revised sine function model. Plots of the difference in observed degree-days at detection of the the smaller absolute means for the sine

\begin{abstract}
model threshold was reached.
\end{abstract}
- 
first spike versus threshold predictions indicated that the revised model had superior predictive ability compared to the Washington model (Fig. 1A), based on smaller differences in observed minus threshold degree-days.

Downy mildew severity in a previous season was negatively correlated with the
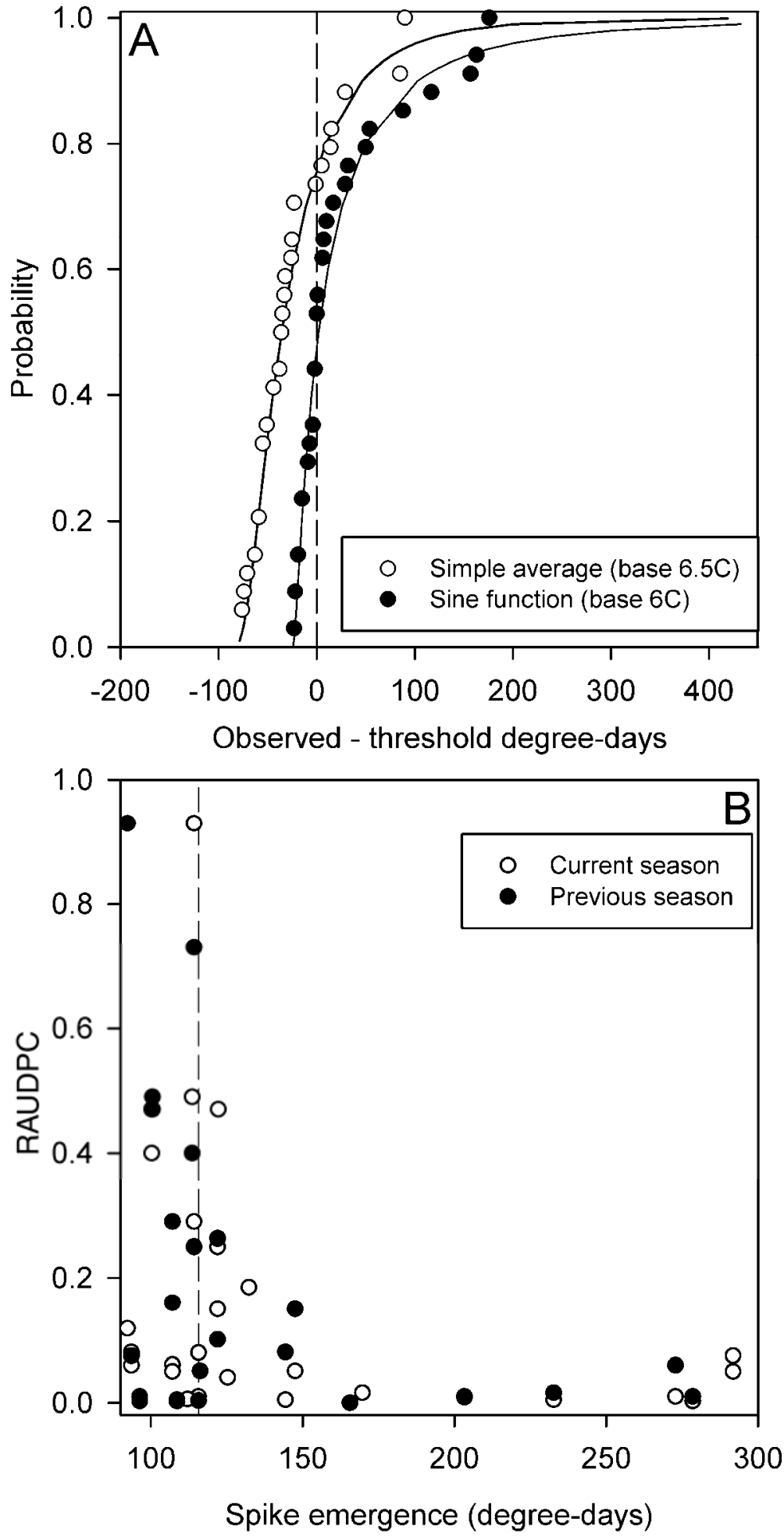

Fig. 1. A, Distribution of prediction errors measured in degree-days based on a simple average degreeday calculation (base $6.5^{\circ} \mathrm{C}$ ) or sine function (base $6.0^{\circ} \mathrm{C}$ ) for prediction of first emergence of hop shoots systemically infected with Pseudoperonospora humuli (spike) in western Oregon. Both models assume a biofix date of 1 February (8). The solid lines in A represent predicted probabilities of emergence of basal spikes based on a three-parameter lognormal model fit to observations from 34 hop yards surveyed in Oregon from 2005 to 2008. B, Association between spike emergence (measured by sine function degree-day model) and relative area under the disease progress curve (RAUDPC) in the current and previous season. The vertical dashed line in B indicates a degree-day threshold of 115.7. Data in $\mathbf{B}$ are from 29 hop yards (current season) or 23 hop yards (previous season).

degree-day emergence date of spikes the following year $(r=-0.39 ; P=0.065)$ (Fig. 1B). In some instances, spikes emerged before the accumulated degree-days neared the threshold of 115.7 when disease severity the previous season was below the median RAUDPC (0.06), although the converse was not observed. That is, spikes consistently emerged near or before the degree-day threshold in yards in which downy mildew was more severe than the average for all yards surveyed the previous season. Median degree-day emergence of spikes was 141 degree-days in yards in which the RAUDPC was less than 0.06 the previous season versus 113 degree-days in yards with RAUDPC greater than 0.06 the previous season. The median degree-days were significantly different $(P=0.045)$ for those two groups of yards as measured by Mood's median test. Severity of disease in the current season and accumulated degree-days at spike emergence in that yard were not significantly associated $(r=$ $-0.31 ; \quad P=0.103)$, and the median RAUDPC were similar for yards in which spikes emerged before or after the degreeday threshold $(P=0.104)$.

Disease risk index validation. The severity of downy mildew varied substantially among years, and in all experiments disease severity in the nontreated plots exceeded that typically observed in commercial hop yards for that season. The AUDPC for basal spikes ranged from 1.1 (2005) to 226.7 (2006) for the grower standard treatment, and was significantly less than that of the nontreated in 2005 and 2007, but not in 2006 or 2008 (Table 2; Fig. 2A, C, E, G). The AUDPC for basal spikes was similar in each year for the grower standard and risk index-timed treatments (Table 2; Fig. 2A, C, E, and G). For treatments initiated using a degree-day threshold, the AUDPC for basal spikes was similar to or less than that of the grower standard plot. The degree-day/copper treatment in 2007 (Fig. 2E) and degreeday/fosetyl-Al treatment in 2006 (Fig. 2C) had significantly lower AUDPC than the grower standard treatment. Unlike in 2006 and 2007, in 2008 the AUDPC for degreeday/fosetyl-Al was not significantly different from the nontreated plot. The number of diseased shoots per plant was variable in 2008 due in part to low temperatures that restricted early-season spread that potentially accentuated plant-to-plant variability related to systemic crown infections. Consequently, plot-to-plot variability was high and disease assessments may not have accurately reflected control of secondary disease spread.

AUDPC for aerial spikes was significantly reduced in 2005 (Fig. 2B), 2006 (Fig. 2D), and 2007 (Fig. 2F) by the grower standard compared to the nontreated plots. Disease severity was significantly greater in the risk index treatment plots compared to the grower standard plot 
in 2005 (Fig. 2B) and 2007 (Fig. 2F), but statistically similar between these treatments in 2006 (Fig. 2D). Treatments initiated at the degree-day threshold had AUDPC values for aerial spikes similar to or less than the grower standard in all experiments. Treatments that commenced at the degree-day threshold had significantly less disease on basal shoots than the nontreated, with the exception of the degree-day/fosetyl-Al treatment in 2006. Only trace levels of cone infection were detected in any of the 4 years, and incidence of downy mildew on cones did not differ significantly among the treatments (data not presented).

\section{DISCUSSION}

This research demonstrated that the emergence of basal spikes can be predicted as a function of thermal time, and that the emergence of basal spikes is also associated with disease severity the previous season. These studies also indicate that hop downy mildew in western Oregon can be managed effectively with fewer fungicide applications than currently made by hop growers in this region. Timing the first fungicide application to coincide with the predicted emergence of basal spikes coupled with later fungicide applications timed based on a risk index resulted in disease suppression similar or superior to that of a typical grower fungicide program, but with four fewer fungicide applications. These findings have practical implications for management of hop downy mildew in western Oregon and suggest that control measures applied in early spring strongly influence the severity of the disease later in the season.

The degree-day model appropriate for Cluster-type hop cultivars grown in Washington was inadequate in western Oregon, where relatively severe outbreaks of downy mildew occur most years (31). Although some of these differences may be attributed to differences in cultivars grown in Oregon versus Washington, we observed little difference among the three cultivars in emergence of basal spikes in this study. Differences in levels of initial inoculum of $P$. humuli likely were more important for the earlier emergence of basal spikes found in the current study as compared to Washington. The severity of downy mildew in western Oregon typically is much greater than in hop yards in the Yakima Valley of Washington (31). Given the significant negative correlation between disease severity the previous season and the degreedays when spikes emerged in the spring, it is not surprising that basal spikes emerged at a lower degree-day threshold in Oregon than that reported in Washington (8).

In Washington, the degree-day model developed by Johnson (8) was designed to predict the first emergence of basal spikes on a regional basis as a conservative means to begin disease scouting and monitoring. The model was not designed necessarily to make predictions about when spikes might emerge within a specific yard because severe downy mildew outbreaks do not occur annually in hop production regions in Washington $(9,12)$. In this study, we designed a degree-day model to predict the emergence of basal spikes in individual yards, which is related in part to the amount of inoculum overwintering from the previous season $(10,12)$. Consequently, the range and relative standard deviation associated with the degree-day models were considerably larger than the degreeday models used to predict emergence of basal spikes on a regional basis in Washington (8). A limitation of using a single degree-day threshold to forecast spike emergence is that a single threshold ignores variability among yards. The probabilistic approach to forecasting the likelihood that a basal spike has emerged may be a more effective approach. As an example, the probability of spike emergence and accumulated degree-days based on the sine function model with a base of $6^{\circ} \mathrm{C}$ was plotted as a function of the 30-year (1978 to 2008) average daily temperatures for
Corvallis, OR (Fig. 3). The threshold of 115.7 degree-days represents the point on the curve that indicates a $50 \%$ probability that a basal spike has emerged, which corresponds to 27 March (rounded-up) based on the 30-year average temperature. Forecasts that predict the probability that a basal spike has emerged could be issued to growers, who would then integrate this with information about downy mildew severity for that yard the previous season, cultivar susceptibility, and other practical considerations to decide the appropriate timing of the initial fungicide application.

The risk index evaluated in this study appears promising for scheduling fungicide applications, although the increase in AUDPC observed for aerial spikes in plots receiving the risk index treatment compared to the grower standard treatment in 2008 is of concern. Several factors may influence the fidelity of the risk index, including severity of downy mildew, cultivar susceptibility, fungicide mode of action, and the action-threshold used to indicate the need for a fungicide application. Additionally, plant wetness associated with periods of rain is required for the index to record risk units, and plant wetness associated with dew alone was ignored in the risk index calculations. In semi-arid environments, wetness from dew may be important for infection of hop by $P$. humuli (32), although in Europe severe outbreaks reportedly are associated only with periods of rain $(14,25)$. In the current study, the risk index was evaluated under very high disease pressure in experimental plots planted to the highly susceptible cultivar Nugget, which represented a near worstcase scenario compared to disease severity in commercial hop production in western Oregon. The action-threshold of 500 risk units was appropriate in England (26), although this action-threshold is empirical and may be too high for western Oregon and/or highly susceptible cultivars such as Nugget. Methods such as receiver operating characteristic curve analysis (34) could

Table 2. Effect of various disease forecasting models on number of fungicide applications and severity of downy mildew on hop cultivar Nugget in western Oregon

\begin{tabular}{|c|c|c|c|c|c|c|c|c|c|c|c|}
\hline \multirow[b]{3}{*}{ Treatment $^{\mathrm{z}}$} & \multicolumn{3}{|c|}{$2005^{y}$} & \multicolumn{3}{|c|}{$2006^{y}$} & \multicolumn{3}{|c|}{$2007^{y}$} & \multicolumn{2}{|c|}{$2008^{y}$} \\
\hline & \multirow[b]{2}{*}{ Applic. } & \multicolumn{2}{|c|}{ AUDPC } & \multirow[b]{2}{*}{ Applic. } & \multicolumn{2}{|c|}{ AUDPC } & \multirow[b]{2}{*}{ Applic. } & \multicolumn{2}{|c|}{ AUDPC } & \multirow[b]{2}{*}{ Applic. } & \multirow{2}{*}{$\begin{array}{c}\text { AUDPC } \\
\text { Basal }\end{array}$} \\
\hline & & Basal & Aerial & & Basal & Aerial & & Basal & Aerial & & \\
\hline Nontreated & 0 & $62.8 \mathrm{a}$ & $1.7 \mathrm{a}$ & 0 & 290.9 a & $44.9 \mathrm{a}$ & 0 & $1,434.6 \mathrm{a}$ & $56.0 \mathrm{a}$ & 0 & $547.3 \mathrm{a}$ \\
\hline Standard & 6 & $1.1 \mathrm{~b}$ & $0.2 \mathrm{c}$ & 8 & $226.7 \mathrm{ab}$ & $2.8 \mathrm{~b}$ & 10 & $174.7 \mathrm{~b}$ & $0.7 \mathrm{c}$ & 8 & $92.9 \mathrm{ab}$ \\
\hline Index & 3 & $3.1 \mathrm{~b}$ & $0.7 \mathrm{~b}$ & 3 & $245.8 \mathrm{ab}$ & $7.5 \mathrm{ab}$ & 5 & $274.1 \mathrm{~b}$ & $6.6 \mathrm{~b}$ & 3 & $131.3 \mathrm{ab}$ \\
\hline Degree-day/copper & $\ldots$ & $\ldots$ & $\ldots$ & 4 & $127.6 \mathrm{bc}$ & $10.9 \mathrm{ab}$ & 6 & $35.9 \mathrm{c}$ & $0 \mathrm{~d}$ & 4 & $87.5 \mathrm{~b}$ \\
\hline Degree-day/fosetyl-Al & $\ldots$ & $\ldots$ & $\ldots$ & 4 & $100.6 \mathrm{c}$ & $6.6 \mathrm{~b}$ & 6 & $89.4 \mathrm{bc}$ & $3.4 \mathrm{cb}$ & 4 & $273.0 \mathrm{ab}$ \\
\hline
\end{tabular}

${ }^{y}$ AUDPC = area under the disease progress curve. Disease severity was determined by counting the number of systemically infected shoots on the base of each hill (basal spikes) or lateral branches (aerial spikes). Aerial spikes were not enumerated in 2008.

${ }^{\mathrm{z}}$ All plots were treated with a fungicide program that consisted of a rotation of fosetyl-Al (Aliette WDG), cymoxanil and copper hydroxide (Curzate 60DF and Kocide 2000), and trifloxystrobin and copper hydroxide (Flint and Kocide 2000) applied at the highest rates allowable by registrations on hop. Fungicide applications in plots receiving the standard treatment were made every 7 to 14 days. Fungicide applications for the index treatment were applied according to a disease forecast index developed by Royle (25), using an action threshold of 500 index points. In plots receiving degree-day/copper and degree-day/fosetyl-Al model treatments, fungicide applications began after the accumulation of 111.3 (Celsius) growing degree-days $\left(\right.$ base $6.0^{\circ} \mathrm{C}$ ) from a biofix date of 1 February. The first fungicide applied to plots was either copper hydroxide (copper) or fosetyl-Al. Subsequent applications were timed according to the disease forecast index. 

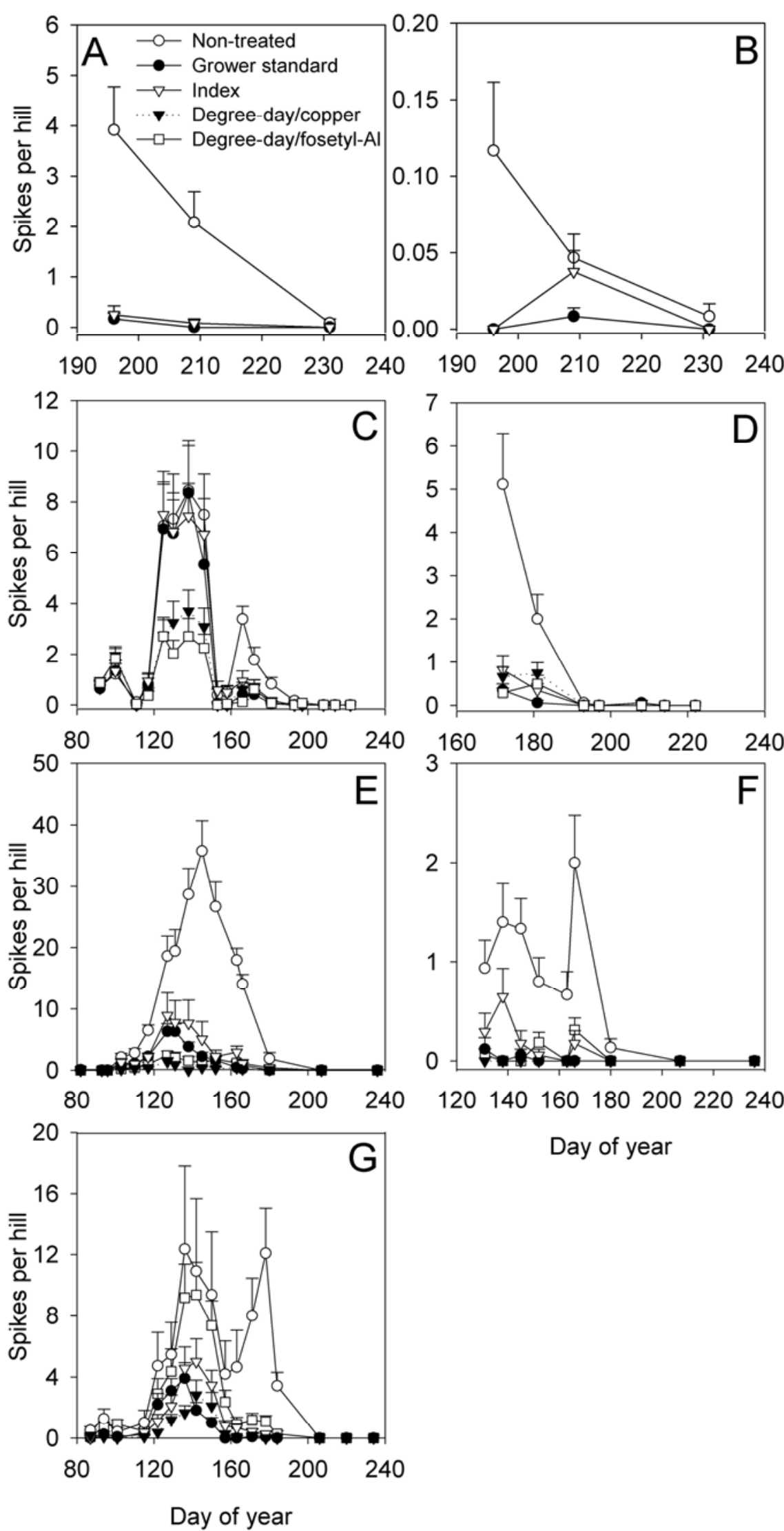

Fig. 2. Disease progress curves for hop downy mildew managed with routine fungicide applications (Grower standard treatment), applications timed according to a risk index (Index), and degree-day models coupled to a risk index (Degree-day/copper and Degree-day/fosetyl-Al). Details of treatments are given in the text. Data for basal spikes are presented in $\mathbf{A}, \mathbf{C}, \mathbf{E}$, and $\mathbf{G}$, and data for aerial spikes are presented in B, D, and F, for 2005 (A and B), 2006 (C and D), 2007 (E and F), and 2008 (G). Each data point is the mean of at least three replications + standard error of the mean. be helpful in deriving optimal actionthresholds that consider economic costs associated with correct or incorrect management decisions.

Interestingly, the physical mode of action of the fungicide used for the first application did not appear critical when timed according to the degree-day model. Both copper and fosetyl-Al provided similar disease suppression in trials in 2006 to 2008. Fosetyl-Al has a high degree of systemic activity and generally superior efficacy against downy mildew as compared to the contact fungicide copper hydroxide (18). It is therefore surprising that the level of downy mildew suppression was similar. Other characteristic of these fungicides, such as environmental persistence, may affect their efficacy when applied early in the season to young hop shoots.

Other limitations of the risk index for scheduling fungicide applications for control of downy mildew have been discussed previously (26) and include logistical constraints associated with management of the disease after infection has occurred, access to high-quality weather data, and grower aversion to a perception of increased risk of a disease outbreak when not following a calendar-based fungicide program (21). In the current study, we applied a rotation of commercially available fungicides that have some level of postinfection activity and applied treatments within $48 \mathrm{~h}$ of predicted infection events, when weather conditions allowed. Hop farms in the United States typically are too large to allow for such a rapid response after a prediction of infection. Delivery of forecasts of model predictions with sufficient lead-time to implement appropriate management responses would greatly improve the practical utility of this (and other) disease forecasting systems. In other research, we have evaluated risk index predictions when operated with downscaled, sitespecific weather analysis and forecasts estimated by Fox Weather, LLC (Fortuna, CA). In that research, weather estimation errors in 2007 appeared to overestimate risk index values, although these differences may not reflect differences in what the optimum management decision should be since the management action-threshold of 500 risk units was derived empirically in another environment. Linking risk index outputs to weather analysis and forecasts will be pursued in future research.

The results of the current study also may have implications for management of powdery mildew (caused by Podosphaera macularis), another important foliar disease of hop in the Pacific Northwestern United States (3). Turechek et al. (33) suggested that control measures for powdery mildew applied early in the growing season were important for later season management of the disease. Mahaffee et al. (17) noted an association between the date of the first fungicide application and the 


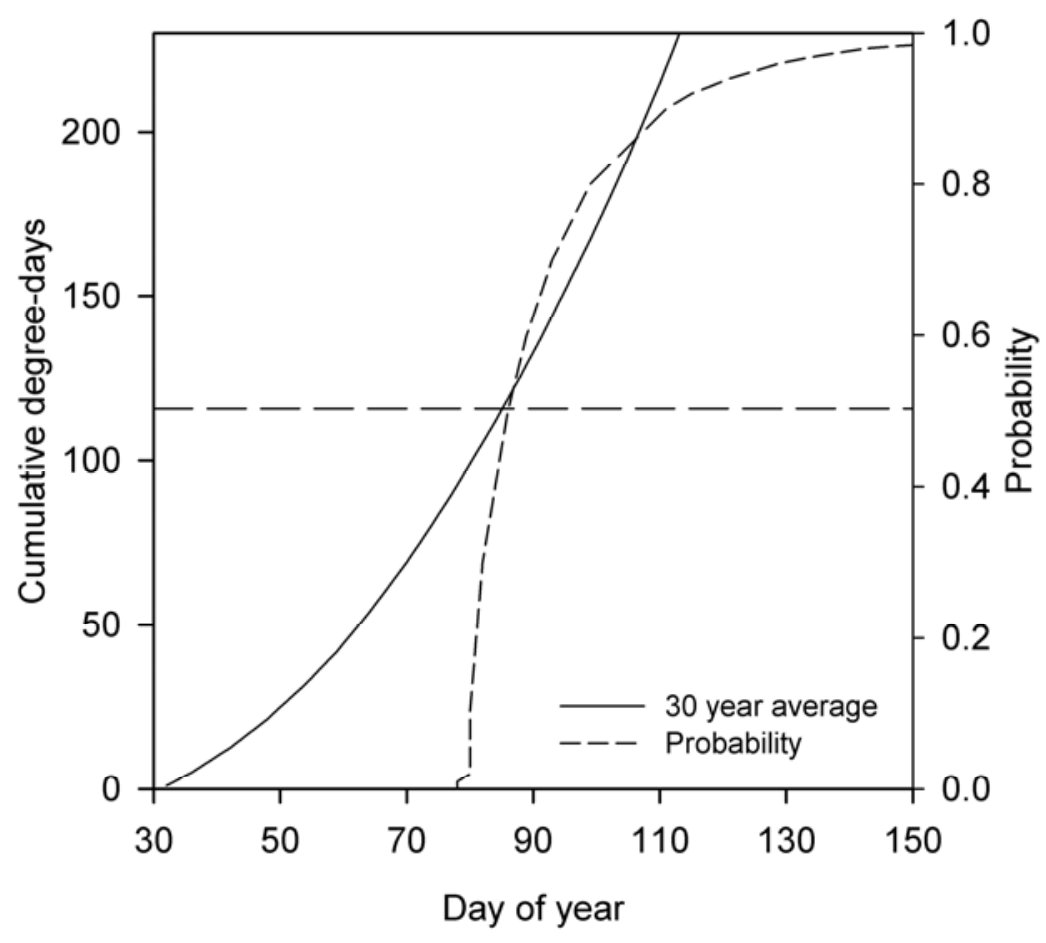

Fig. 3. Average cumulative degree-days for a base temperature $6.0^{\circ} \mathrm{C}$ sine function degree-day model and probability of downy mildew basal spike emergence, based on the 30-year average temperature recorded near Corvallis, OR. The horizontal dashed line represents a threshold of 115.7 degree-days (Celsius) and indicates a 50\% probability that a basal spike has emerged. The $50 \%$ probability corresponds to 27 March (rounded-up) for this location.

incidence of powdery mildew cones at harvest. Application of a fungicide with efficacy against both pathogens $(3,19)$ may positively affect management of powdery mildew. Similar benefits have been reported previously for copper-based fungicides applied to hop yards during vegetative development later in the season (27). Although cultivar Nugget currently is considered resistant to powdery mildew in the United States, other cultivars included in the current study (Glacier and Willamette) are susceptible to both diseases and potentially could benefit from early-season fungicide applications in situations where the severity of downy mildew is expected to be high.

\section{ACKNOWLEDGMENTS}

The authors gratefully acknowledge funding from USDA/CSREES Western Region IPM Grant number ORE00296 entitled "Reduced Fungicide Use for Hop Downy Mildew Management." Additional funding was provided by Hop Research Council, Oregon Hop Commission, Oregon State University, and USDAARS CRIS Project 5358-21000-035-00. We thank Lindsey du Toit and Dennis Johnson for their critical reviews of an earlier draft of the manuscript. We also thank the hop growers who allowed us access to their yards for sampling.

\section{LITERATURE CITED}

1. Coley-Smith, J. R. 1964. Persistence and identification of downy mildew Pseudoperonospora humuli (Miy + Tak) Wilson in hop rootstocks. Ann. Appl. Biol. 53:129-132.

2. Coley-Smith, J. R. 1965. Infection of hop rootstocks by downy mildew Pseudoperonospora humuli (Miy. et Tak.) Wilson and its control by early-season dusts. Ann. Appl. Biol. 56:381-388.

3. Gent, D. H., Nelson, M. E., George, A. E., Grove, G. G., Mahaffee, W. F., Ocamb, C. M.,
Barbour, J. D., Peetz, A., and Turechek, W. W. 2008. A decade of hop powdery mildew in the Pacific Northwest. Online. Plant Health Progress doi:10.1094/PHP-2008-0314-01-RV.

4. Gent, D. H., Nelson, M. E., and Grove, G. G. 2008. Persistence of phenylamide insensitivity in Pseudoperonospora humuli. Plant Dis. 92:463-468.

5. Haunold, A., Likes, S. T., Nickerson, G. B., and Hampton, R. O. 1984. Registration of Nugget hop. Crop Sci. 24:618.

6. Hellwig, K., Kremheller, H. T., and Agerer, R. 1991. Untersuchen zur resistenz von Pseudoperonospora humuli (Miy. \& Tak.) Wilson gegenuber metalaxyl. Gesunde Pflanz. 43:400-404.

7. Hunger, R. M., and Horner, C. E. 1982. Control of hop downy mildew with systemic fungicides. Plant Dis. 66:1157-1159.

8. Johnson, D. A. 1991. Two degree-day models for predicting initial emergence of hop shoots systemically infected with Pseudoperonospora

9. Johnson, D. A., Alldredge, J. R., and Allen, J. R. 1994. Weather and downy mildew epidemics of hop in Washington State. Phytopathology 84:524-527.

10. Johnson, D. A., and Anliker, W. L. 1985. Effect of downy mildew epidemics on the seasonal carryover of initial inoculum in hop yards. Plant Dis. 69:140-142.

11. Johnson, D. A., and Skotland, C. B. 1985. Effects of temperature and relative humidity on sporangium production of Pseudoperonospora humuli on hop. Phytopathology 75:127-129.

12. Johnson, D. A., Skotland, C. B., and Alldredge, J. R. 1983. Weather factors affecting downy mildew epidemics of hops in the Yakima Valley of Washington. Phytopathology 73:490-493.

13. Klein, R. E. 1994. Occurrence and incidence of metalaxyl resistance in Pseudoperonospora humuli in the Pacific Northwest. Plant Dis. 78:161-163.

14. Kremheller, H. Th., and Diercks, R. 1983. Epidemiologie und prognose des falschen humuli. Plant Dis. 75:285-287. mehltaues (Pseudoperonospora humuli) am hopfen. Z. Pflanzenkrankh. Pflanzenschutz 90:599-616.

15. Madden, L. V., Hughes, G., and van den Bosch, F. 2007. The Study of Plant Disease Epidemics. American Phytopathological Society, St. Paul, MN

16. Mahaffee, W. F., Pethybridge, S. J., and Gent, D. H., eds. 2009. Compendium of Hop Diseases and Pests. American Phytopathological Society, St. Paul, MN.

17. Mahaffee, W. F., Thomas, C. S., Turechek, W. W., Ocamb, C. M., Nelson, M. E., Fox, A., and Gubler, W. D. 2003. Responding to an introduced pathogen: Podosphaera macularis (hop powdery mildew) in the Pacific Northwest. Online. Plant Health Progress doi:10.1094/ PHP-2003-1113-07-RV.

18. Nelson, M. E., Eastwell, K. C., Grove, G. G., Barbour, J. D., Ocamb, C. M., and Alldredge, J. R. 2004. Sensitivity of Pseudoperonospord humuli (the casual agent of hop downy mildew) from Washington, Idaho, and Oregon to fosetyl-Al (Aliette). Online. Plant Health Progress doi:10.1094/PHP-2004-0811-01-RS.

19. Nelson, M. E., and Grove, G. G. 2004. Evaluation of fungicides for control of hop downy mildew in Washington's Yakima Valley, 2004 Fungicide and Nematicide Tests (online). Report 60:FC084. DOI: 10.1094/FN60. APS Press, St. Paul, MN.

20. Neve, R. A. 1991. Hops. Chapman and Hall, London.

21. Pannell, D. J. 1991. Pests and pesticides, risk and risk aversion. Agric. Econ. 5:361-383.

22. Pejml, K., Petrlik, Z., and Stys, Z. 1978. Shortterm forecast of downy mildew of hop (Peronoplasmopara humuli Miy. \& Tak.). Ochr. Rostl. 14:41-46.

23. Perez, B. A., Martínez, E., and Barreto, D. 2003. Recent outbreaks of hop downy-mildew disease in the South Andean Region of Argentina. (Abstr.) Phytopathology 93:S71.

24. Romanko, R. R. 1964. Control of hop downy mildew by chemical desiccants. Phytopathology 54:1439-1442.

25. Royle, D. J. 1973. Quantitative relationships between infection by the hop downy mildew pathogen, Pseudoperonospora humuli, and weather and inoculum factors. Ann. Appl. Biol. 73:19-30.

26. Royle, D. J. 1979. Prediction of hop downy mildew to rationalize fungicide use. Rep. Dep. Hop Res. Wye Coll. 1978:49-57.

27. Royle, D. J., and Griffin, M. J. 1973. Sideeffects of downy mildew fungicides on the incidence of hop powdery mildew (Sphaerotheca humuli). Plant Pathol. 22:129-133.

28. Royle, D. J., and Kremheller, H. TH. 1981. Downy mildew of the hop. Pages 395-419 in: The Downy Mildews. D. M. Spencer, ed. Academic Press, New York.

29. Ryan, B., Joiner, B., and Cryer, J. 2005. Minitab Handbook, 5th ed. Brooks/Cole, Belmont, CA.

30. Skotland, C. B. 1961. Infection of hop crowns and roots by Pseudoperonospora humuli and its relation to crown and root rot and overwintering of the pathogen. Phytopathology 51:241-244.

31. Skotland, C. B., and Johnson, D. A. 1983 Control of downy mildew of hops. Plant Dis. 67:1183-1185.

32. Sonoda, R. M., and Ogawa, J. M. 1972. Ecological factors limiting epidemics of hop downy mildew in arid climates. Hilgardia 41:457-473.

33. Turechek, W. W., Mahaffee, W. F., and Ocamb, C. M. 2001. Development of management strategies for hop powdery mildew in the $\mathrm{Pa}$ cific Northwest. Online. Plant Health Progress doi:10.1094/PHP-2001-0313-01-RS.

34. Turechek, W. W., and Wilcox, W. F. 2005. Evaluating predictors of apple scab with receiver operating characteristic curve analysis. Phytopathology 95:679-691. 